\title{
A feasibility study for the retrieval of the total column precipitable water vapour from satellite observations in the blue spectral range
}

\author{
T. Wagner, S. Beirle, H. Sihler, and K. Mies \\ Max Planck Institute for Chemistry, Mainz, Germany \\ Correspondence to: T. Wagner (thomas.wagner@mpic.de)
}

Received: 21 March 2013 - Published in Atmos. Meas. Tech. Discuss.: 12 April 2013

Revised: 11 August 2013 - Accepted: 28 August 2013 - Published: 8 October 2013

\begin{abstract}
We present a new algorithm for satellite retrievals of the atmospheric water vapour column in the blue spectral range. The water vapour absorption cross section in the blue spectral range is much weaker than in the red spectral range. Thus the detection limit and the uncertainty of individual observations are systematically larger than for retrievals at longer wavelengths. Nevertheless, water vapour retrievals in the blue spectral range have also several advantages: since the surface albedo in the blue spectral range is similar over land and ocean, water vapour retrievals are more consistent than for longer wavelengths. Compared to retrievals at longer wavelengths, the sensitivity for atmospheric layers close to the surface is higher due to the (typically 2 to 3 times) higher ocean albedo in the blue. Water vapour retrievals in the blue spectral range are also possible for satellite sensors, which do not measure at longer wavelengths of the visible spectral range like the Ozone Monitoring Instrument (OMI). We investigated details of the water vapour retrieval in the blue spectral range based on radiative transfer simulations and observations from the Global Ozone Monitoring Experiment 2 (GOME-2) and OMI. It is demonstrated that it is possible to retrieve the atmospheric water vapour column density in the blue spectral range over most parts of the globe. The findings of our study are of importance also for future satellite missions (e.g. Sentinel 4 and 5).
\end{abstract}

\section{Introduction}

Water vapour is the most important natural greenhouse gas (e.g. Held and Soden, 2000, and references therein; Solomon et al., 2007), drives the hydrological cycle and also plays an important role in many chemical reactions. In contrast to most other greenhouse gases, the atmospheric water vapour distribution is highly variable. Thus continuous time-series measurements of atmospheric water vapour, in particular on global scale, are important. Several algorithms for the retrieval of the total column precipitable water vapour from satellite observations have been developed in the last decades (note that in the following we use the term "vertical column density", VCD, for the vertically integrated $\mathrm{H}_{2} \mathrm{O}$ concentration). These algorithms include measurements in various parts of the electromagnetic spectrum (e.g. in the microwave, infrared and visible spectral ranges). An important advantage of measurements in the microwave spectral range is that they are possible in the presence of clouds (e.g. Bauer and Schluessel, 1993). However, meaningful retrievals are usually only possible over the oceans. Measurements in the thermal infrared spectral range are possible over both ocean and land, and they can yield (limited) information on the vertical distribution in the troposphere (Jedlovec, 1985; Soden and Bretherton, 1996; Tobin et al., 2006; Shepard et al., 2008). However, usually such observations have only limited sensitivity for the lowest part of the atmospheric column. Also they are strongly affected by clouds; thus typically cloudcovered observations have to be skipped, and the resulting data sets are biased towards clear sky conditions. Observations in the near-IR and red spectral range allow the retrieval of the $\mathrm{H}_{2} \mathrm{O}$ VCD (including the surface near layers), but are also strongly affected by clouds. Because of the rather low surface albedo, observations over ocean have typically larger uncertainties than over land. Also for such observations the sensitivity for the surface near layers is reduced (Noël et al., 1999, 2008; Maurellis et al., 2000; Bennartz and Fischer, 2001; Lang et al., 2003; Lang and Lawrence, 2004; Wagner et al., 2003, 2006; Mieruch et al., 2008). 
Here we present a new algorithm for the retrieval of the $\mathrm{H}_{2} \mathrm{O}$ VCD from satellite observations in the blue spectral range. Although the water vapour absorption cross section in that spectral range is about 25 times smaller than in the red spectral range (see Fig. 1), we demonstrate that it is possible to retrieve the atmospheric water vapour column from satellite measurements in the blue spectral range for most parts of the globe.

Measurements in the blue spectral range have important advantages compared to measurements in the red and nearIR spectral range:

- Since the surface albedo is more homogenous in the blue spectral range compared to longer wavelengths, the retrieved $\mathrm{H}_{2} \mathrm{O}$ data sets are more consistent, especially across land-ocean boundaries. In particular the sensitivity towards the surface-near layers is similar over land and ocean. Here it should be noted that the albedo dependence on the retrieved $\mathrm{H}_{2} \mathrm{O}$ VCDs can in principle be corrected if accurate knowledge about the surface albedo, cloud properties and $\mathrm{H}_{2} \mathrm{O}$ profile is available. However, usually this is not the case, and especially in the retrievals in the red spectral range, the associated uncertainties are rather high (see Sect. 3).

- In the blue spectral range the surface albedo is higher over the oceans than for longer wavelengths causing an increased sensitivity towards the surface-near layers.

- Because of the stronger Rayleigh scattering in the blue spectral range, also the effects of clouds are weaker compared to longer wavelengths.

- Because of the weak $\mathrm{H}_{2} \mathrm{O}$ absorption, no saturation correction has to be applied.

- In addition to these fundamental advantages, retrievals in the blue spectral range allow also the analysis of the $\mathrm{H}_{2} \mathrm{O}$ VCD from sensors like Ozone Monitoring Instrument (OMI), which do not cover wavelengths $>500 \mathrm{~nm}$. The retrieval of the $\mathrm{H}_{2} \mathrm{O} \mathrm{VCD}$ from OMI spectra in the blue spectral range will provide a unique data set with almost daily global coverage for a long time period (2004 to present and beyond).

Most of these aspects are confirmed by the results presented Sects. 3 and 4.

In this study, we first introduce the new $\mathrm{H}_{2} \mathrm{O}$ retrieval in the blue spectral range and apply it to Global Ozone Monitoring Experiment 2 (GOME-2) and OMI observations (Sect. 2). GOME-2 observations have the advantage that they also cover the red spectral range. Thus the results from the blue spectral range can be directly compared to those from existing retrievals in the red spectral range for the same instrument. In Sect. 3, we investigate the sensitivity of $\mathrm{H}_{2} \mathrm{O}$ retrievals in the blue spectral range based on radiative transfer simulations. We quantify the effects of clouds and compare

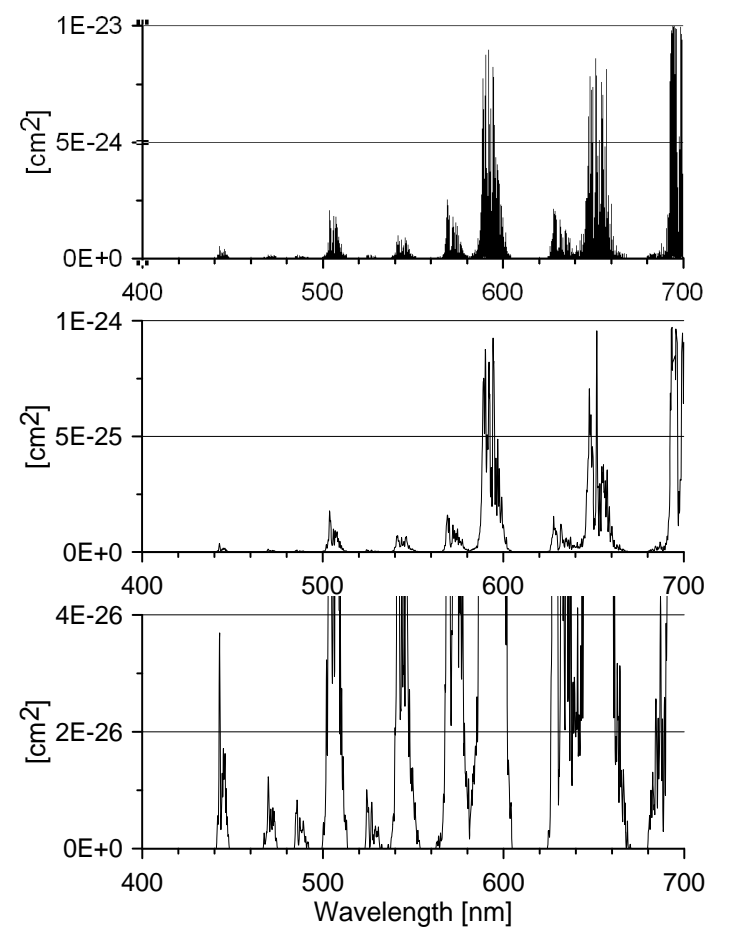

Fig. 1. High-resolution $\mathrm{H}_{2} \mathrm{O}$ absorption cross section from the HITRAN database for $290 \mathrm{~K}$ (Rothman et al., 2005) (top panel) and convolved to a spectral resolution of $0.4 \mathrm{~nm}$ (FWHM) (middle and bottom panels). In the bottom panel the maximum of the $y$ axis is set to $4 \times 10^{-26} \mathrm{~cm}^{2}$ to visualise the weak absorption band around $443 \mathrm{~nm}$ better.

the results in both spectral ranges. In Sect. 4 retrieval results from GOME-2 and OMI observations are presented and compared with the results from the radiative transfer simulations. Also the uncertainties and detection limit of the new retrieval algorithm are investigated.

\section{Spectral analysis}

For the analysis of the water vapour absorption in the blue spectral range, we chose the same settings for GOME-2 on METOP and OMI on AURA: a wavelength interval between 430 and $450 \mathrm{~nm}$ is used. Besides the water vapour absorption cross section (for $290 \mathrm{~K}$ and $1013 \mathrm{hPa}$, taken from the HITRAN database; see Rothman et al., 2005), also the cross sections of $\mathrm{NO}_{2}$ (for $294 \mathrm{~K}$, Vandaele et al., 1997) and $\mathrm{O}_{3}$ (for $341 \mathrm{~K}$, Bogumil et al., 2003) as well as a Ring spectrum (Wagner et al., 2009) were included. The original cross sections were convolved by the respective instrument slit functions of both sensors, which have a full width at half maximum (FWHM) in the blue spectral range of about $0.51 \mathrm{~nm}$ (GOME-2) and $0.55 \mathrm{~nm}(\mathrm{OMI})$. A direct sun spectrum and a polynomial of degree 5 were also fitted to correct the strong Fraunhofer lines and possible broadband spectral features. The wavelength calibration was performed 


\begin{tabular}{|c|c|c|c|}
\hline . & $\begin{array}{l}\text { GOME-2, } \\
\text { weak } \mathrm{H}_{2} \mathrm{O} \\
\text { absorption } \\
01.06 .2007 \\
05: 48: 41 \mathrm{UTC} \\
\text { lat } 62.2^{\circ}, \text { lon } \\
81.5^{\circ}, \mathrm{SZA}: \\
43.7^{\circ} \\
\text { average radiance: } \\
1.6 \cdot 10^{13} \\
\text { photons } /\left(\mathrm{cm}^{2} \mathrm{~s} \mathrm{sr}\right. \\
\text { nm) } \\
\mathrm{H}_{2} \mathrm{O} \mathrm{SCD}: \\
(3.6 \pm 1.7) \cdot 10^{22} \\
\text { molecules } / \mathrm{cm}^{2}\end{array}$ & (5) & $\begin{array}{l}\text { GOME-2 } \\
\text { strong } \mathrm{H}_{2} \mathrm{O} \\
\text { absorption } \\
01.06 .2007 \\
06: 04: 10 \mathrm{UTC} \\
\text { lat } 8.6^{\circ} \text {, lon } \\
59.2^{\circ}, \mathrm{SZA} \text { : } \\
35.7^{\circ} \\
\text { average radiance: } \\
5.1 \cdot 10^{13} \\
\text { photons } /\left(\mathrm{cm}^{2} \mathrm{~s} \mathrm{sr}\right. \\
\text { nm) } \\
\mathrm{H}_{2} \mathrm{O} \mathrm{SCD}: \\
(29.7 \pm 1.4) \cdot 10^{22} \\
\text { molecules } / \mathrm{cm}^{2}\end{array}$ \\
\hline - & $\begin{array}{l}\text { OMI } \\
\text { weak } \mathrm{H}_{2} \mathrm{O} \\
\text { absorption } \\
01.06 .2007 \\
08: 55: 22 \mathrm{UTC} \\
\text { lat } 60.8^{\circ}, \text { lon } \\
57.6^{\circ}, \mathrm{SZA}: \\
39.7^{\circ} \\
\text { average radiance: } \\
3.4 \cdot 10^{13} \\
\text { photons } /\left(\mathrm{cm}^{2} \mathrm{~s} \mathrm{sr}\right. \\
\text { nm) } \\
\mathrm{H}_{2} \mathrm{O} \mathrm{SCD}: \\
(3.9 \pm 2.9) \cdot 10^{22} \\
\text { molecules } / \mathrm{cm}^{2}\end{array}$ & (1.0) & $\begin{array}{l}\mathrm{OMI} \\
\text { strong } \mathrm{H}_{2} \mathrm{O} \\
\text { absorption } \\
01.06 .2007 \\
08: 54: 42 \mathrm{UTC} \\
\text { lat } 58.5^{\circ}, \text { lon } \\
59.1^{\circ}, \mathrm{SZA}: \\
37.7^{\circ} \\
\text { average radiance: } \\
9.5 \cdot 10^{13} \\
\text { photons } /\left(\mathrm{cm}^{2} \mathrm{~s} \mathrm{sr}\right. \\
\text { nm) } \\
\mathrm{H}_{2} \mathrm{O} \mathrm{SCD}: \\
(20.8 \pm 2.3) \cdot 10^{22} \\
\text { molecules } / \mathrm{cm}^{2}\end{array}$ \\
\hline
\end{tabular}

Fig. 2. Examples of the spectral analyses for selected GOME-2 (top panels) and OMI (bottom panels) measurements. The red lines indicate the reference spectra scaled to the retrieved optical depths plus residual in the measured spectra (black). In the left part spectra with weak $\mathrm{H}_{2} \mathrm{O}$ absorption and in the right part with strong $\mathrm{H}_{2} \mathrm{O}$ absorption were chosen.

using a high-resolution solar spectrum (Kurucz et al., 1984). For GOME-2, all measurements were analysed with one set of reference spectra. For OMI, for each row of the twodimensional detector, individual sets of reference spectra were prepared. The result of the spectral analysis, the socalled $\mathrm{H}_{2} \mathrm{O}$ slant column density ( $\mathrm{SCD}$ ), represents the integrated $\mathrm{H}_{2} \mathrm{O}$ concentration along the atmospheric light paths.

In Fig. 2 examples of the spectral retrieval for both instruments are presented. For the cases with high atmospheric water vapour content (right part of Fig. 2), the $\mathrm{H}_{2} \mathrm{O}$ absorption feature at $442 \mathrm{~nm}$ can be clearly identified. However, for cases with low $\mathrm{H}_{2} \mathrm{O}$ content, the $\mathrm{H}_{2} \mathrm{O}$ absorption feature is similar or even weaker than the spectral residual. The typical uncertainties of the retrieved $\mathrm{H}_{2} \mathrm{O} S C D$ as determined from the DOAS fit range from $1 \times 10^{22}$ to $2.5 \times 10^{22}$ molec cm $^{-2}$ for GOME- 2 and from $3 \times 10^{22}$ to $5 \times 10^{22} \mathrm{molec} \mathrm{cm}^{-2}$ for
OMI. As can be seen in Fig. 2, the magnitude of the residual is smaller for spectra with higher radiances, caused for example by clouds or high surface albedo. It is interesting to note that the uncertainty of the $\mathrm{H}_{2} \mathrm{O}$ retrieval is about a factor of two higher for OMI than for GOME-2, probably caused by a smaller signal-to-noise ratio of the OMI instrument. Here it should be noted that this reduced signal-to-noise ratio is not caused by a potential bad instrument performance, but is related to the much smaller ground pixel sizes compared to GOME-2. The uncertainty is about one order of magnitude larger than for the $\mathrm{H}_{2} \mathrm{O}$ retrieval in the red spectral range (see also Sect. 4.1 and Table 2).

We also investigated the uncertainties of the spectral retrieval by varying several fit settings (wavelength range, degree of polynomial, $\mathrm{H}_{2} \mathrm{O}$ cross section). The effects of these changes were quantified by comparing the fit results for one 

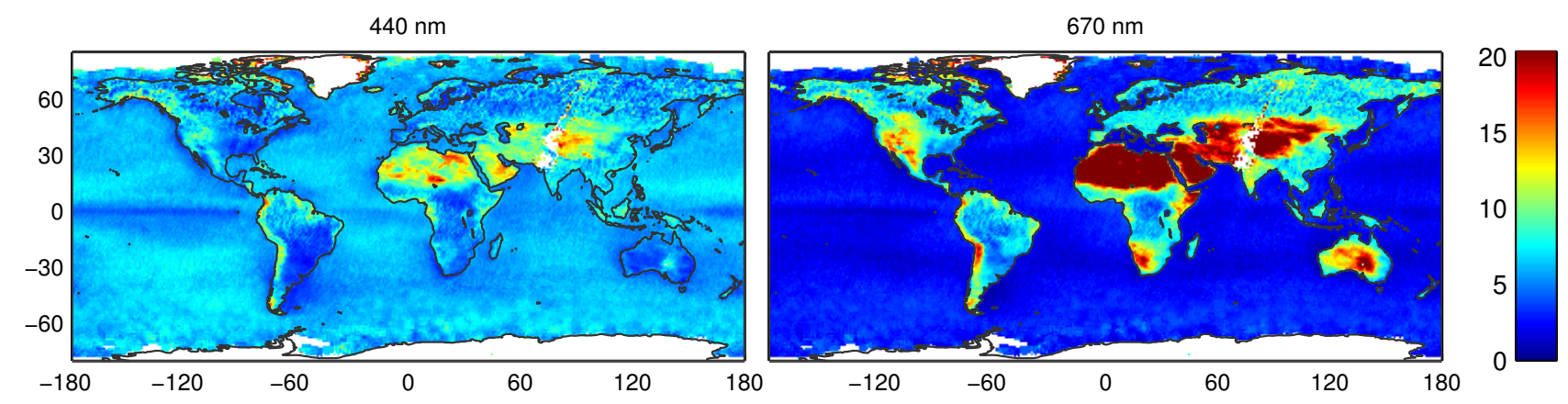

Fig. 3. Annually averaged surface albedo (1996-2003) at $440 \mathrm{~nm}$ (left panel) and $670 \mathrm{~nm}$ (right panel) derived from GOME observations. Data are taken from the TEMIS database (http://www.temis.nl/data/ler.html, Koelemeijer et al., 2003).

GOME-2 orbit with the results of the standard settings (described above). Varying the fit windows (lower edge between 424 and $436 \mathrm{~nm}$, upper edge between 444 and $460 \mathrm{~nm}$ ) and the degree of the polynomials (3-5) leads to differences of the retrieved $\mathrm{H}_{2} \mathrm{O}$ SCDs between $-1.29 \times 10^{22}$ and $1.24 \times 10^{22}$, which are of the order of the fit errors or below. If the $\mathrm{H}_{2} \mathrm{O}$ cross section is replaced by the HITRAN 2009 version (see Rothman et al., 2009, and http: //www.cfa.harvard.edu/hitran/), an even smaller difference of $-0.23 \times 10^{22}$ is found.

To date it is not possible to identify the optimum settings for the spectral retrieval. This should be subject to future validation studies after $\mathrm{H}_{2} \mathrm{O}$ VCDs have been calculated from the retrieved $\mathrm{H}_{2} \mathrm{O}$ SCDs.

\section{Radiative transfer simulations}

To determine the $\mathrm{H}_{2} \mathrm{O}$ VCDs, the retrieved $\mathrm{H}_{2} \mathrm{O}$ SCDs are divided by the so-called air mass factor (AMF):

$\mathrm{VCD}=\mathrm{SCD} / \mathrm{AMF}$

Usually the AMF is derived from radiative transfer simulations (Noxon et al., 1979; Solomon et al., 1987).

In this study we do not convert the retrieved $\mathrm{H}_{2} \mathrm{O}$ SCDs into VCDs. This will be an extensive task as it has to take into account in detail the effects of varying surface albedo, surface elevation, and cloud properties such as effective cloud fraction and cloud altitude. Thus it will be the focus of future work. Here we calculate AMFs to explore the measurement sensitivity for various measurement conditions. In particular we compare AMFs for observations in the blue spectral range with those for the red spectral range. Here it should be noted that (a) a higher AMF indicates a higher sensitivity of the measurement, and (b) that a higher AMF leads to smaller uncertainties of the $\mathrm{H}_{2} \mathrm{O}$ VCDs calculated from the retrieved $\mathrm{H}_{2} \mathrm{O}$ SCDs (see also discussion at the end of this section and Table 3).

In addition to AMFs for the total $\mathrm{H}_{2} \mathrm{O} V C D$, we also calculate so-called box-AMF (BAMF) for individual height layers:

$\Delta \mathrm{VCD}_{i}=\Delta \mathrm{SCD}_{i} / \mathrm{BAMF}_{i}$.

Here $\triangle \mathrm{VCD}_{i}$ and $\triangle \mathrm{SCD}_{i}$ represent the partial vertical and slant column density of the atmospheric layer $i$. The $\mathrm{BAMF}_{i}$ is a measure of the sensitivity of the observation for a specific altitude layer $i$.

We calculated AMFs and profiles of $\mathrm{BAMF}_{i}$ for satellite observations of atmospheric water vapour using the full spherical Monte Carlo radiative transfer model McARTIM (Deutschmann et al., 2011). For the determination of the total $\mathrm{H}_{2} \mathrm{O}$ AMF, we assumed an exponentially decreasing profile of the water vapour concentration with a scale height of $2 \mathrm{~km}$. Simulations were performed for cloud-free and cloudcovered satellite pixels. Partially cloud-covered observations were described by the so-called independent pixel approximation: the AMFs (or BAMF $_{i}$ ) of the clear and cloudy part of a satellite ground pixel are averaged (weighted by the cloud fraction and the top of the atmosphere radiances of the clear and cloudy parts). For the cloudy part horizontally homogenous clouds of $1 \mathrm{~km}$ vertical thickness at different altitudes and with different optical depths were assumed. As a scattering phase function, a Henyey-Greenstein approximation with an asymmetry parameter of 0.85 was used. For the surface albedo, different values were assumed for the blue $(6 \%$ over ocean and land) and red (2\% over ocean and $15 \%$ over land) spectral ranges (see Fig. 3). These choices are not representative of all ocean and land surfaces, but reflect the general tendencies that over ocean the surface albedo is usually larger in the blue spectral range and vice versa over land. The simulations were performed for a nadir-viewing instrument (elevation angle $-90^{\circ}$ ) at an altitude of $800 \mathrm{~m}$; the solar zenith angle (SZA) was set to zero, but similar results were also found for other SZAs (note that no sun glint effects were taken into account). It should also be noted that, for simplicity, the simulations in the red spectral range were made assuming $\mathrm{H}_{2} \mathrm{O}$ to be a weak absorber, which is usually not the case. Thus the calculated AMFs in the red spectral range have to be seen as upper limits for the true AMF (e.g. Wagner et al., 2003). 


\section{Ocean}

Clear

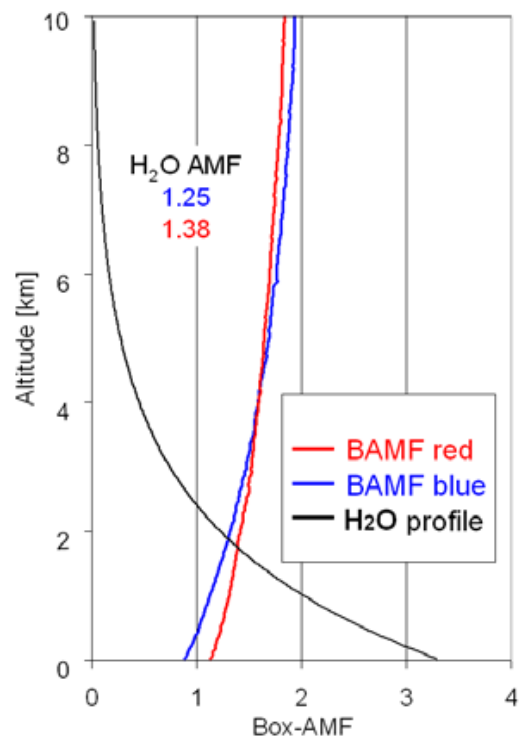

Land

Clear

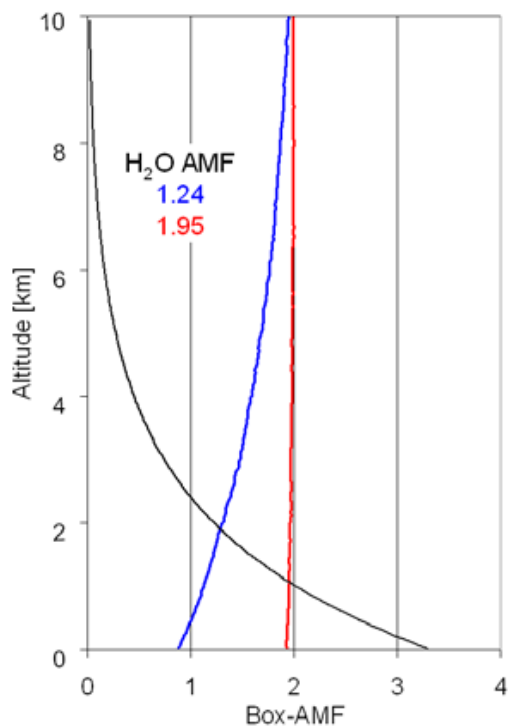

COD: $20, \mathrm{CF}_{\text {eff: }}: 10 \%$

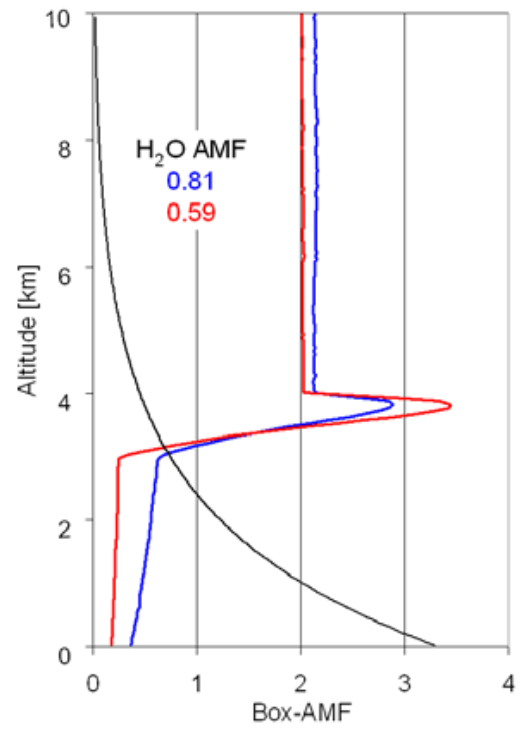

COD: $20, \mathrm{CF}_{\text {eff }}: 10 \%$

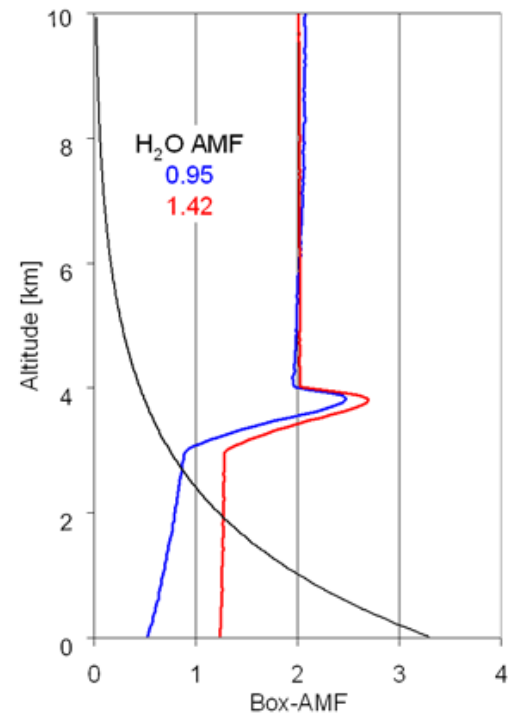

COD: $20, \mathrm{CF}_{\text {eff: }}: 10 \%$

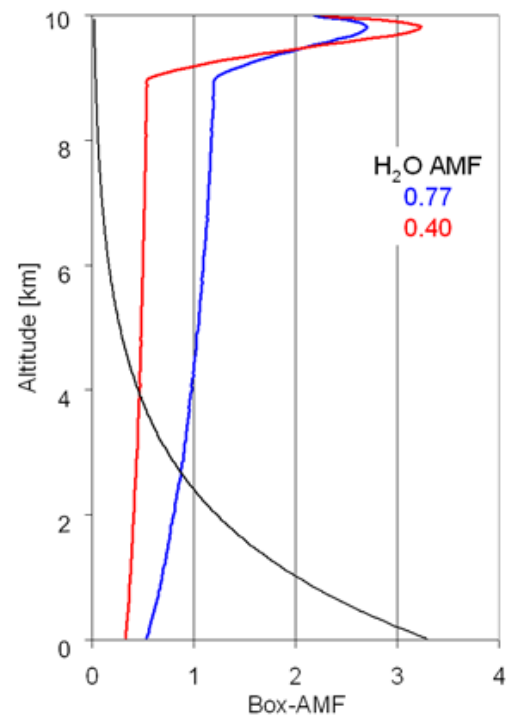

COD: $20, \mathrm{CF}_{\text {eff: }} 10 \%$

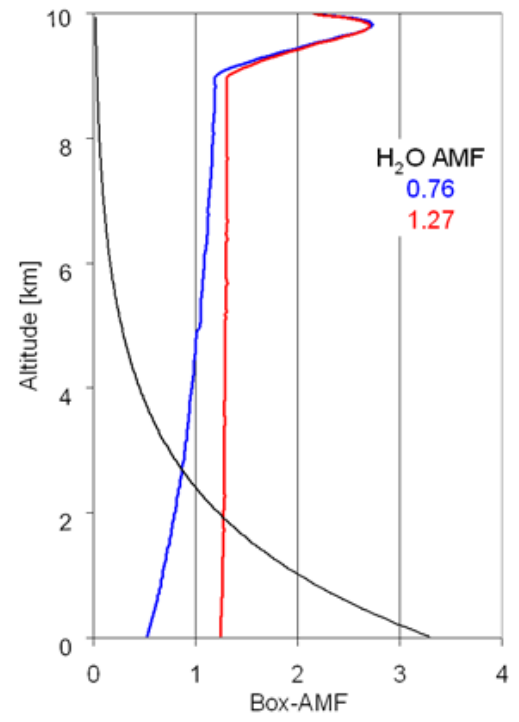

Fig. 4. Profiles of BAMF $i$ for satellite observations in the blue and red spectral range for clear skies (left panels) and partly cloud-covered pixels (10\% effective cloud fraction) with cloud altitude between 3 and $4 \mathrm{~km}$ (centre panels) and 9 and $10 \mathrm{~km}$ (right panels). The upper panel shows results for ocean (surface albedo $6 \%$ in the blue and $2 \%$ in the red spectral range); the lower panel shows results for land (surface albedo $6 \%$ in the blue and $15 \%$ in the red spectral range). $\mathrm{H}_{2} \mathrm{O}$ AMFs for both spectral ranges are shown inside the individual figures. The black lines indicate relative $\mathrm{H}_{2} \mathrm{O}$ concentration profiles with a scale height of $2 \mathrm{~km}$.

Figure 4 presents profiles of $\mathrm{BAMF}_{i}$ over land and ocean for both spectral ranges. For observations over cloud-free pixels (left part of Fig. 4), the sensitivity decreases towards the surface for all assumed combinations of wavelengths and surface albedos. However, for observations at $630 \mathrm{~nm}$ over land (surface albedo: $15 \%$ ), the decrease is only very weak, because of the weak contribution of Rayleigh scattering to the observed light at longer wavelengths. The total AMFs are always larger for observations in the red spectral range.

For observations over partly clouded ground pixels (effective cloud fraction: $10 \%$ ), the sensitivity is almost constant above the cloud, shows a maximum in the upper part of the 
Table 1. Comparison of $\mathrm{H}_{2} \mathrm{O}$ AMFs for satellite observations over ocean (top) and land (bottom) for different effective cloud fractions, cloud altitudes and cloud optical thickness. The effective cloud fraction was calculated according to the radiative transfer simulation results in the red spectral range.

\begin{tabular}{|c|c|c|c|c|c|c|c|c|c|c|}
\hline \multirow{2}{*}{$\begin{array}{l}\text { Cloud } \\
\text { properties }\end{array}$} & \multicolumn{2}{|c|}{$\mathrm{CF}_{\text {eff }}: 0 \%$} & \multicolumn{2}{|c|}{$\mathrm{CF}_{\mathrm{eff}}: 10 \%$} & \multicolumn{2}{|c|}{$\mathrm{CF}_{\mathrm{eff}}: 20 \%$} & \multicolumn{2}{|c|}{$\mathrm{CF}_{\mathrm{eff}}: 50 \%$} & \multicolumn{2}{|c|}{$\mathrm{CF}_{\mathrm{eff}}: 80 \%$} \\
\hline & Blue & Red & Blue & Red & Blue & Red & Blue & Red & Blue & Red \\
\hline \multicolumn{11}{|c|}{ Ocean (blue surface albedo: $6 \%$, red surface albedo: $2 \%$ ) } \\
\hline CTH: 4 km, COD: 10 & 1.25 & 1.38 & 0.98 & 0.73 & 0.84 & 0.61 & 0.66 & 0.52 & & \\
\hline CTH: 4 km, COD: 20 & 1.25 & 1.38 & 0.96 & 0.72 & 0.81 & 0.59 & 0.62 & 0.49 & 0.54 & 0.46 \\
\hline CTH: $10 \mathrm{~km}, \mathrm{COD}: 10$ & 1.25 & 1.38 & 0.80 & 0.42 & 0.57 & 0.24 & 0.20 & 0.10 & & \\
\hline CTH: $10 \mathrm{~km}, \mathrm{COD}: 20$ & 1.25 & 1.38 & 0.77 & 0.40 & 0.53 & 0.22 & 0.22 & 0.07 & 0.10 & 0.03 \\
\hline \multicolumn{11}{|c|}{ Land (blue surface albedo: $6 \%$, red surface albedo: $15 \%$ ) } \\
\hline CTH: 4 km, COD: 10 & 1.25 & 1.95 & 0.97 & 1.46 & 0.83 & 1.19 & 0.66 & 0.83 & & \\
\hline CTH: 4 km, COD: 20 & 1.25 & 1.95 & 0.95 & 1.42 & 0.80 & 1.14 & 0.61 & 0.73 & 0.54 & 0.57 \\
\hline CTH: $10 \mathrm{~km}, \mathrm{COD}: 10$ & 1.25 & 1.95 & 0.77 & 1.31 & 0.54 & 0.95 & 0.26 & 0.49 & & \\
\hline CTH: $10 \mathrm{~km}$, COD: 20 & 1.25 & 1.95 & 0.76 & 1.27 & 0.52 & 0.90 & 0.22 & 0.37 & 0.11 & 0.17 \\
\hline
\end{tabular}

Table 2. Comparison of the scatter (standard deviation) of the $\mathrm{H}_{2} \mathrm{O}$ SCDs retrieved from the different sensors, spectral ranges and overlap regions. Unit: $10^{22}$ molec $\mathrm{cm}^{-2}$.

\begin{tabular}{lccc}
\hline $\begin{array}{l}\text { Region/ } \\
\text { latitude range }\end{array}$ & $\begin{array}{c}\text { GOME-2 } \\
\text { red }\end{array}$ & $\begin{array}{c}\text { GOME-2 } \\
\text { blue }\end{array}$ & $\begin{array}{c}\text { OMI } \\
\text { blue }\end{array}$ \\
\hline Greenland/76 to $80^{\circ}$ & 0.04 & 0.63 & 1.12 \\
Southern Ocean/ -42 to $-46^{\circ}$ & 0.33 & 1.89 & 3.29 \\
Eastern Europe 49 to $55^{\circ}$ & 0.80 & 1.73 & 2.86 \\
\hline
\end{tabular}

cloud and decreases strongly towards the cloud bottom. Below the cloud, the sensitivity further decreases until the surface. For observations over low surface albedo, the sensitivity below the cloud is generally smaller than for observations over high surface albedo. While for observations over land, the AMFs for the red spectral range are still systematically larger than in the blue spectral range, over ocean the opposite is found. This is an important finding, because most of the satellite pixels are partly covered by clouds. Similar results are also obtained for other cloud fractions (see Table 1).

Finally, we investigated the uncertainties of the AMF calculations for both spectral ranges for different surface albedos and cloud fractions. In Table 3, the uncertainties of the respective AMF are shown, which are caused by variations of the surface albedo by $1 \%$ (absolute uncertainty). Especially over ocean, the uncertainties in the blue spectral range are much smaller than in the red spectral range. Over land, the uncertainties are similar, except over deserts, where the uncertainties in the red spectral range are smaller.

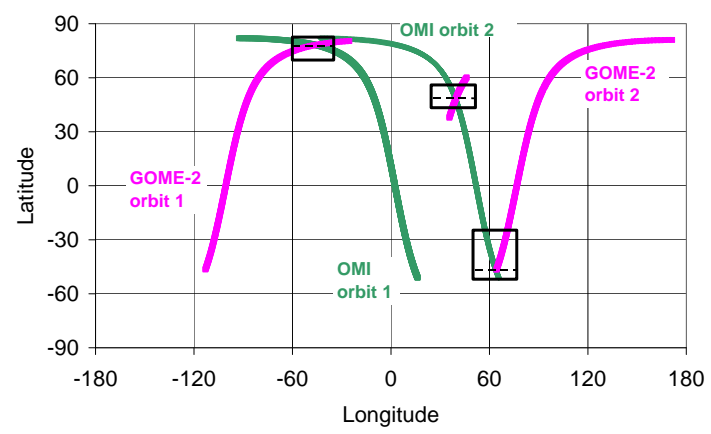

Fig. 5. Selected orbits of GOME-2 (pink) and OMI (green) for 1 June 2007, which are investigated in this study (only nadir observations are used). The black rectangles indicate overlap regions used for comparison (cf. Fig. 8).

\section{Results from GOME-2 and OMI}

We applied the new algorithm to measurements for June 2007 from GOME-2 (on METOP; see EUMETSAT, 2005) and OMI (on AURA; see Levelt and Noordhoek, 2002). GOME-2 observations cover the UV, visible and nearIR spectral range. Thus they allow a direct comparison of the results of both spectral ranges for the same measurements. Note that the $\mathrm{H}_{2} \mathrm{O}$ SCDs in the red spectral are analysed according to Wagner et al. (2006, 2011). OMI observations provide daily global coverage and have a better spatial resolution compared to the GOME-2 instrument.

\subsection{Results for individual orbits}

For our comparison study, we first chose selected orbits on 1 June 2007 (see Fig. 5). We limit this study to nadir measurements alone, for which the atmospheric radiation transport is similar for both sensors. The only difference is a 
Table 3. Relative change of the $\mathrm{AMF}^{\mathrm{a}}$ for a change in surface albedo of $1 \%$.

\begin{tabular}{lrc}
\hline Scenario & $\begin{array}{r}\text { Red } \\
\text { spectral } \\
\text { range }\end{array}$ & $\begin{array}{c}\text { Blue } \\
\text { spectral } \\
\text { range }\end{array}$ \\
\hline Ocean $^{\mathrm{b}}$ clear sky & $10 \%$ & $4 \%$ \\
Ocean $^{\mathrm{b}} 10 \%$ cloud fraction & $35 \%$ & $7 \%$ \\
Land $^{\mathrm{c}}$ clear sky & $2 \%$ & $4 \%$ \\
Land $^{\mathrm{c}} 10 \%$ cloud fraction & $7 \%$ & $7 \%$ \\
Desert $^{\mathrm{d}}$ clear sky & $0.5 \%$ & $1 \%$ \\
Desert $^{\mathrm{d}} 10 \%$ cloud fraction & $1 \%$ & $2 \%$ \\
\hline
\end{tabular}

${ }^{a}$ For an exponential profile with scale height of $2 \mathrm{~km}$.

b Assumed surface albedo over ocean: red spectral range: $2 \%$, blue spectral range: $6 \%$.

${ }^{c}$ Assumed surface albedo over land: red spectral range: $8 \%$, blue spectral range: $6 \%$.

${ }^{\mathrm{d}}$ Assumed surface albedo over desert: red spectral range: $30 \%$, blue spectral range: $15 \%$.
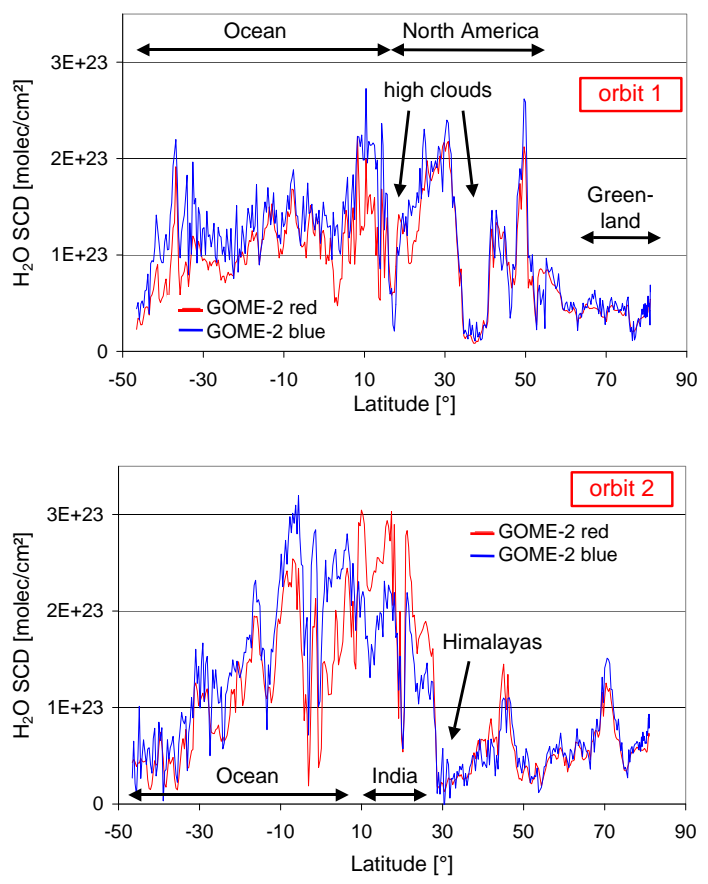

Fig. 6. $\mathrm{H}_{2} \mathrm{O} \mathrm{SCD}$ for the first (top panel) and second (bottom panel) selected GOME-2 orbit on 1 June 2007 (Fig. 5). Note that only nadir observations were considered. High values are found in both spectral ranges over the tropics, low values over high clouds or high mountains like the Himalayas. Over ocean, in general the values from the blue spectral range are larger than those from the red spectral range. Over land, often the results from the red spectral range are larger, or the results from both analyses are similar.

different SZA due to the different overpass times. Since GOME-2 and OMI observations are made on the descending and ascending parts of the orbits, respectively, collocated measurements are only found for the crossing points of the selected orbits (black rectangles in Fig. 5).
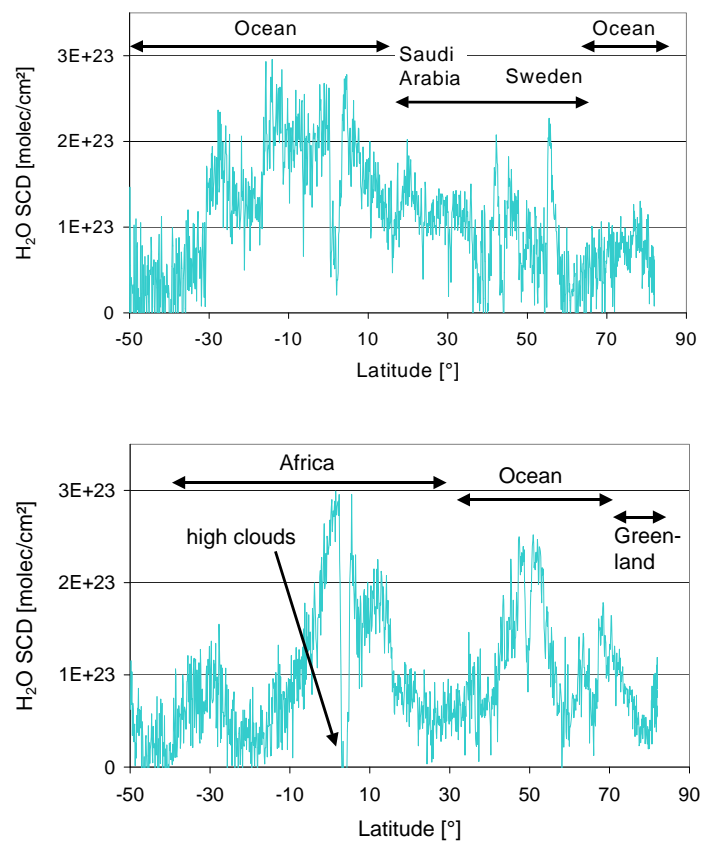

Fig. 7. $\mathrm{H}_{2} \mathrm{O}$ SCDs for the first (top panel) and second (bottom panel) selected OMI orbit on 1 June 2007 (Fig. 5). Note that only nadir observations were considered. High values are usually found over the tropics; low values are found over high clouds.

In Fig. 6, results for the two selected full GOME-2 orbits are shown. Similar latitudinal variations are found for the results from the red and blue spectral range. However, the $\mathrm{H}_{2} \mathrm{O}$ SCDs retrieved in the blue spectral range show a higher scatter caused by the much weaker cross section. As expected from the radiative transfer simulations, over ocean the $\mathrm{H}_{2} \mathrm{O}$ SCDs retrieved in the blue spectral range are higher than those retrieved in the red spectral range. Over land, the $\mathrm{H}_{2} \mathrm{O}$ SCDs retrieved in the red spectral range are higher than those retrieved in the blue spectral range, or both results are similar. The lowest values are found for measurements over high clouds or high mountains like the Himalayas.

In Fig. 7, $\mathrm{H}_{2} \mathrm{O}$ SCDs for both selected OMI orbits are shown. Again, the highest $\mathrm{H}_{2} \mathrm{O}$ SCDs are observed over the tropics, and the lowest values over high clouds. Compared to the GOME-2 results from the blue spectral range, the scatter of the $\mathrm{H}_{2} \mathrm{O}$ SCDs retrieved from OMI is larger, and for very low $\mathrm{H}_{2} \mathrm{O} S C D$ s even negative values can be found. The larger scatter reflects the smaller signal-to-noise ratio of the OMI observations (due to smaller ground pixels) compared to GOME-2.

In Fig. 8, the results of both instruments are compared for three selected parts around the overlap regions (see Fig. 5). The selected locations represent observations over high albedo (Greenland), low surface albedo (ocean), and intermediate surface albedo values (eastern Europe). For the selected cases, in general good agreement is found between both instruments. Remaining differences are probably caused 

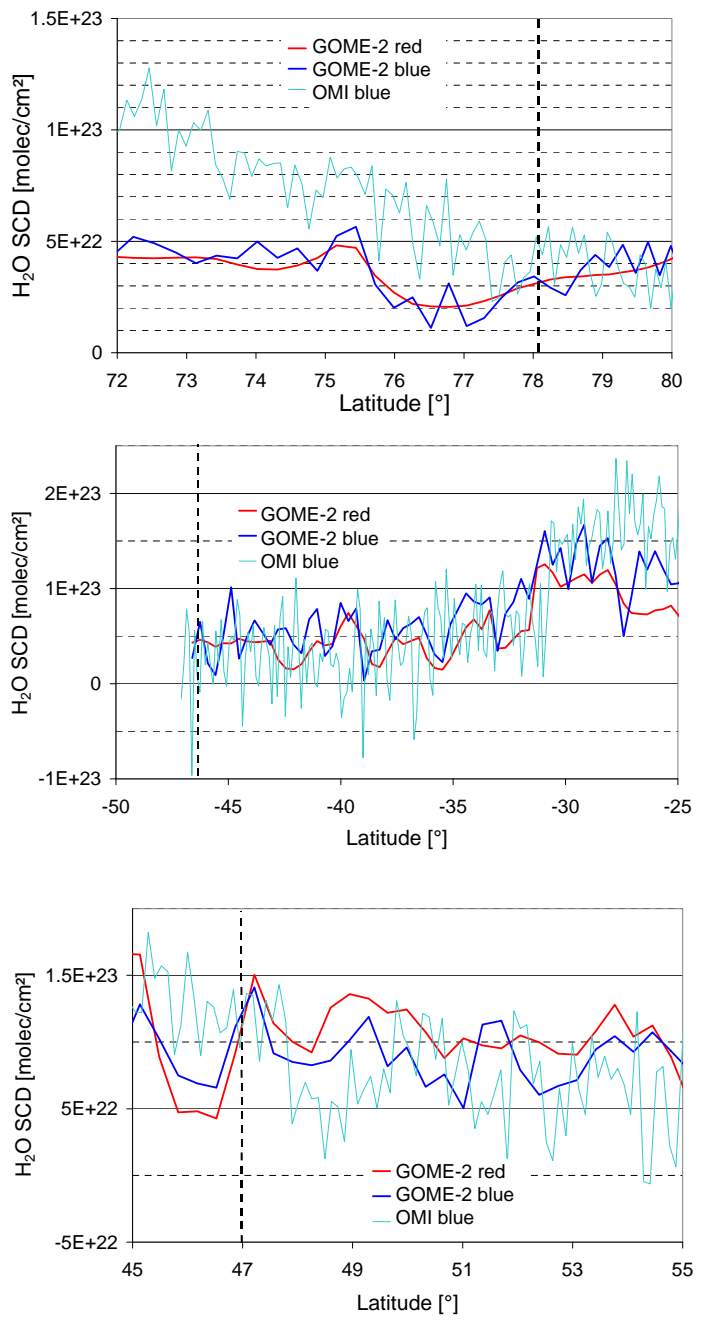

Fig. 8. Comparison of the $\mathrm{H}_{2} \mathrm{O}$ SCDs retrieved from both instruments in the selected overlap regions over Greenland (top panel), the Southern Ocean (middle panel) and eastern Europe (bottom panel) (see black rectangles in Fig. 5). Note that only nadir observations were considered. The exact locations of the overlap region are indicated by the vertical black dashed lines.

by the relatively large time difference (about $4 \mathrm{~h}$ ), differences in location, and the different SZA. Again the scatter of the $\mathrm{H}_{2} \mathrm{O}$ SCDs is smallest for the analysis in the red spectral range, and the scatter of the OMI results is larger compared to the GOME-2 results from the blue spectral range. Over Greenland, where the surface albedo is high (ice and snow), the scatter is much smaller than over the ocean, where the albedo is low.

We quantified the scatter of the $\mathrm{H}_{2} \mathrm{O}$ SCDs from the different analyses and regions in the following way: first, we selected latitude ranges around the overlap regions (for Greenland the latitude range between 76 and $80^{\circ}$, for the Southern Ocean between -42 and $-46^{\circ}$, and for eastern Europe between 49 and $55^{\circ}$ were chosen). Second, we fitted a polynomial of degree 4 to the $\mathrm{H}_{2} \mathrm{O}$ SCDs within the selected latitude ranges. Third, the fitted polynomials were subtracted from the $\mathrm{H}_{2} \mathrm{O}$ SCDs, and the standard deviations were determined. The respective values for the different spectral ranges, instruments and latitude ranges are presented in Table 2.

For GOME-2, the scatter of the results from the red spectral range is up to about one order of magnitude less compared to the blue spectral range. The scatter of the OMI results is about a factor of two larger than for the GOME-2 results from the blue spectral range. Over eastern Europe and over the Southern Ocean, the scatter is about a factor of 3 (blue spectral range) or 8 to 20 (red spectral range) larger than over Greenland. This is caused by the strong difference in surface albedo, which is especially large in the red spectral range. It should, however, be noted that especially over eastern Europe also the natural variability of the $\mathrm{H}_{2} \mathrm{O}$ VCD contributes to the determined standard deviation (see the rather high values for the red spectral range). Note that, for the comparison over Greenland, south of about $77.5^{\circ}$ latitude, the $\mathrm{H}_{2} \mathrm{O}$ SCDs retrieved from OMI are systematically larger than those from GOME-2. This difference is caused by the different locations of the respective orbits (GOME-2 over central Greenland; OMI over the eastern edge of Greenland and over the ocean).

\subsection{Daily and monthly mean maps}

Figure 9 shows global maps of the $\mathrm{H}_{2} \mathrm{O} \mathrm{SCD}$ retrieved from GOME-2 (in the red and blue spectral ranges) and OMI (in the blue spectral range). In the left part results for one selected day (1 June 2007) are displayed. In the right part monthly mean values for June 2007 are shown. For both daily and monthly maps, the measurements are averaged on a $0.5^{\circ} \times 0.5^{\circ}$ grid. Only measurements with effective cloud fractions $<10 \%$ are considered in the monthly means in order to minimise the effects of clouds.

In general, good agreement of the spatial patterns in all data sets is found. However, as expected also systematic differences appear (see Fig. 10): over the oceans (except sunglint), usually the $\mathrm{H}_{2} \mathrm{O}$ SCDs retrieved in the blue spectral range are larger than those retrieved in the red spectral range because of the smaller surface albedo in the red spectral range (see Sect. 3). The opposite is found for most locations over the continents. Exceptions are over the north-west part of South America, over central Africa and South-East Asia, where the surface albedo in the red spectral range is relatively low.

The comparison between GOME- 2 and OMI results from the blue spectral range shows less clear patterns: in the daily data typically higher values in the GOME-2 results are found on the east side of the GOME-2 swath over the tropical oceans, which is caused by sun glint. Sun glint occurs at different viewing angles for both sensors due to the different overpass times. Other differences (positive or negative) are mostly related to variations in cloud cover and atmospheric humidity between the overpass times of both sensors. 

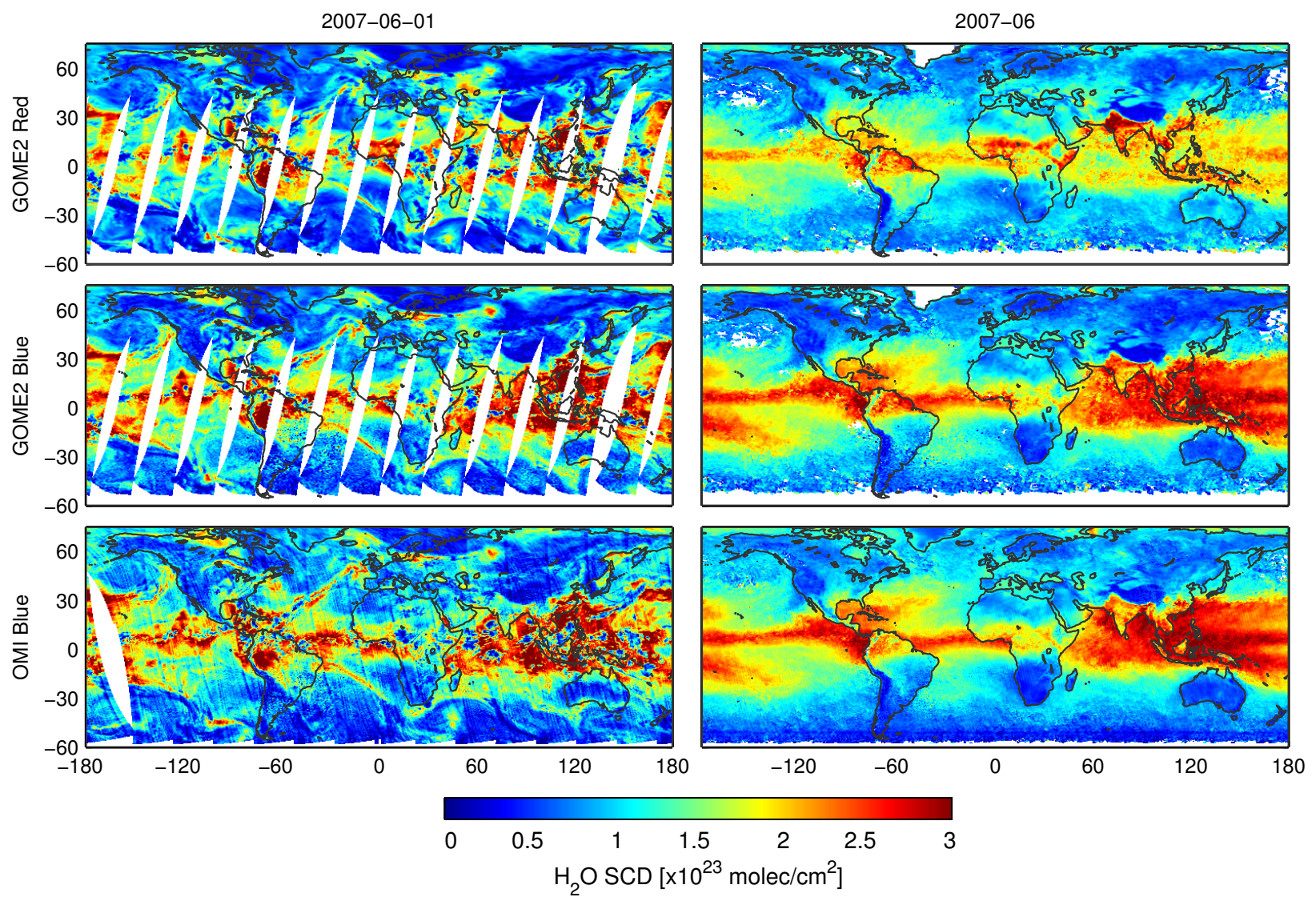

Fig. 9. Global maps of the $\mathrm{H}_{2} \mathrm{O}$ SCDs retrieved from GOME-2 in the red (top panels) and blue spectral range (centre panels) as well as from OMI in the blue spectral range (bottom panels). Left panels: results for one day (1 June 2007); right panels: mean values for June 2007 with spatial resolution of $0.5^{\circ} \times 0.5^{\circ}$. For the monthly mean maps, only measurements with effective cloud fractions $<10 \%$ are considered.

In Fig. 11 the differences in the difference in effective cloud cover between both sensors are shown. Here it should, however, be noted that different cloud retrieval algorithms are used for both instruments (Acarreta et al., 2004; Koelemeijer et al., 2003; Wang et al., 2008).

Especially in mid-latitudes the movement of frontal systems is clearly visible causing systematic structures in the daily difference maps.

For the monthly mean maps in general, similar differences as in the daily maps are found. However, for the comparison between GOME-2 and OMI, the effects of varying cloud cover and sun glint are strongly reduced due to the strict cloud criterion and the statistical compensation of positive and negative deviations in the monthly averages. Interestingly, some systematic differences are still present (e.g. over parts of South America, central Africa, the US east coast and East Asia). These differences can be partly attributed to differences in cloud cover for the different overpass times of both sensors (see Fig. 11). However, for some of the differences, no clear explanation was found. Slightly higher $\mathrm{H}_{2} \mathrm{O}$ SCDs are found in the OMI data over the Northern Hemisphere, probably related to systematic differences of the SZA and relative azimuth angles.
In Fig. 12 and Table 4, results of correlation analyses between the different data sets are presented. In general, good agreement is found. Systematically higher correlation coefficients are found for the comparison of the results from GOME-2 in the blue and red spectral ranges than for the comparison between both instruments. This is mainly caused by the systematic difference in overpass time and pixel size between GOME-2 and OMI. The slopes of the regression lines are close to unity, except for the comparison of the results from GOME-2 in the blue and red spectral ranges over ocean. This finding is caused by the large difference in surface albedo over ocean in both spectral ranges.

\section{Conclusions and outlook}

A new algorithm for satellite retrievals of the atmospheric water vapour column in the blue spectral range is presented. Although the $\mathrm{H}_{2} \mathrm{O}$ absorption cross section in the blue spectral range is about a factor of 25 smaller than in the red spectral range, $\mathrm{H}_{2} \mathrm{O}$ retrievals in the blue spectral range are feasible and have furthermore important advantages: first, because the surface albedo is similar over land and ocean, $\mathrm{H}_{2} \mathrm{O}$ 


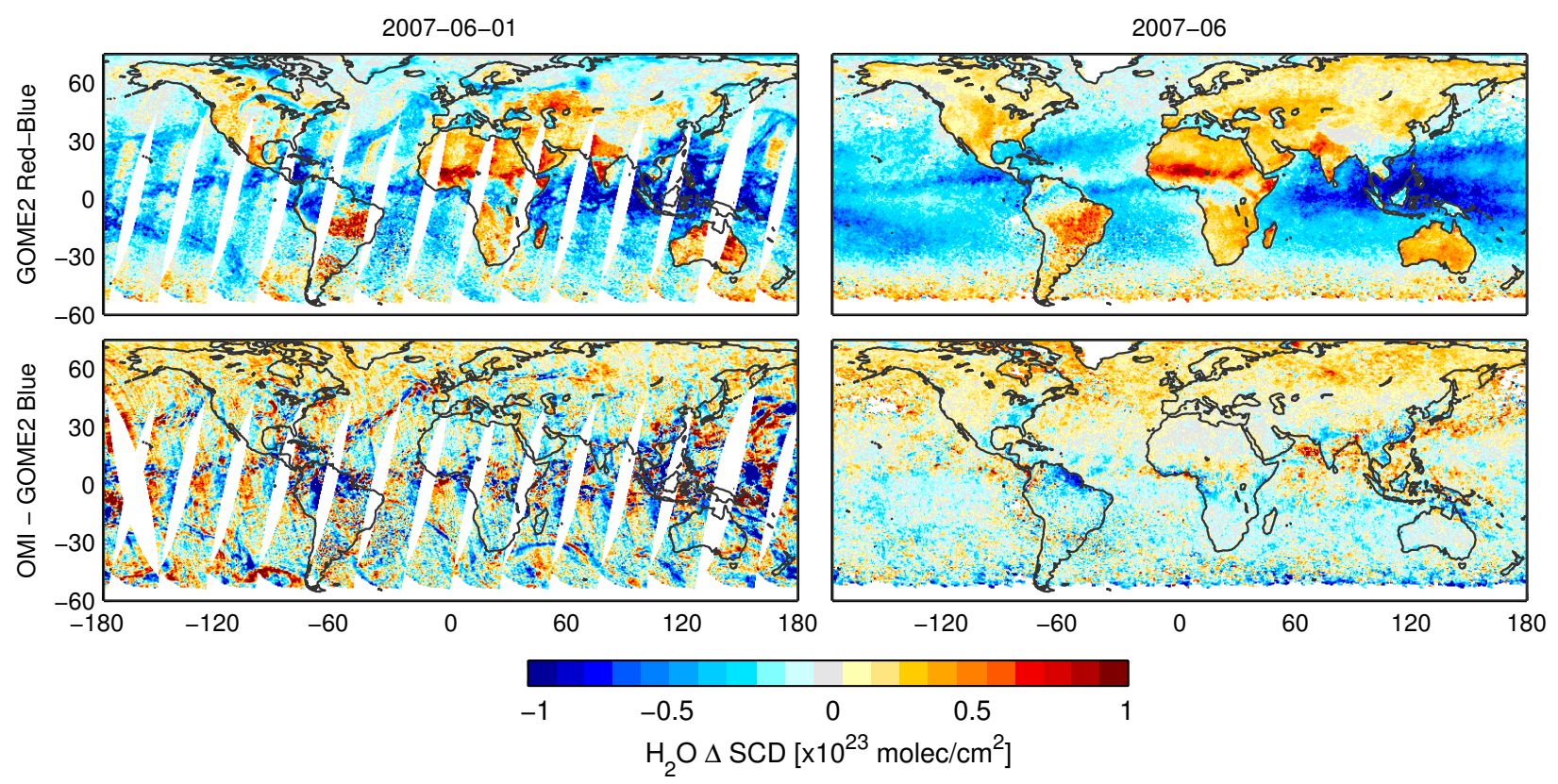

Fig. 10. Differences of the GOME-2 analysis in the red spectral range (top panels) and the OMI analysis in the blue spectral range (bottom panels) compared to the GOME-2 analysis in the blue spectral range for the data shown in Fig. 9. Daily results are shown left, and monthly mean results are shown right.
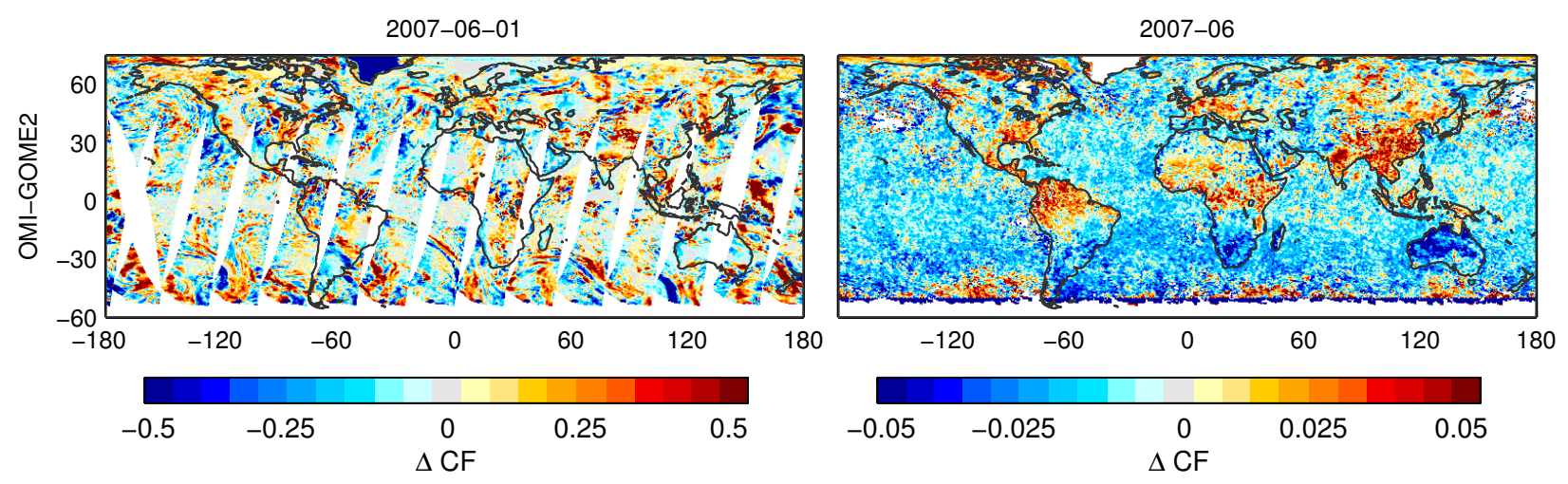

Fig. 11. Differences of the effective cloud fractions measured by OMI and GOME-2 for the data shown in Figs. 9 and 10.

retrievals in the blue spectral range are more consistent than at longer wavelengths. Second, because of the stronger scattering on molecules and the larger surface albedo over ocean, the shielding effect of clouds is weaker than in the red spectral range. Thus, for such observations, the sensitivity for layers close to the surface is higher than at longer wavelengths. Third, because of the weak atmospheric $\mathrm{H}_{2} \mathrm{O}$ absorption in the blue spectral range, no saturation correction is needed. Fourth, $\mathrm{H}_{2} \mathrm{O}$ retrievals in the blue spectral range are also possible for satellite sensors, which do not cover longer wavelengths of the visible spectral range (like OMI).

It should be noted that because of the much smaller absorption cross section, the water vapour columns derived in the blue spectral range have typically much larger uncertainties compared to those derived in the red spectral range (for individual observations). Thus for specific applications (e.g. measurements over regions with a very small atmospheric water vapour content or regions with high surface albedo in the red spectral range), satellite measurements in the red spectral are probably better suited.

We investigated the properties of the new retrieval based on radiative transfer simulations and observations from two different satellite instruments: GOME-2 and OMI. GOME-2 measurements allow a direct comparison of the results from both spectral ranges on the basis of individual measurements. The observations confirmed the results of the radiative transfer simulations, especially with respect to the higher sensitivity of the analysis in the blue spectral range over ocean (and lower sensitivity over land). We also investigated the uncertainty of the analysis in the blue spectral range. We found 
GOME-2 (red) versus GOME-2 (blue), correlation of daily observations

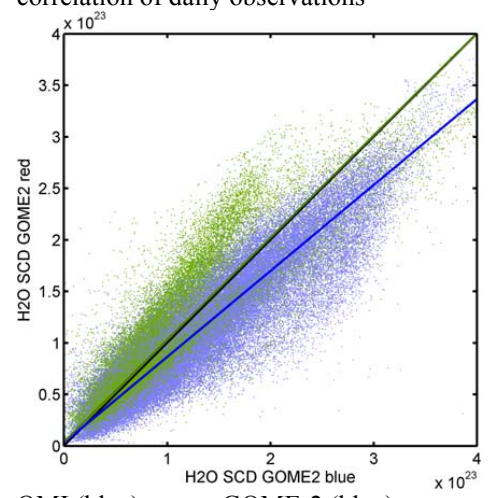

OMI (blue) versus GOME-2 (blue), correlation of daily observations

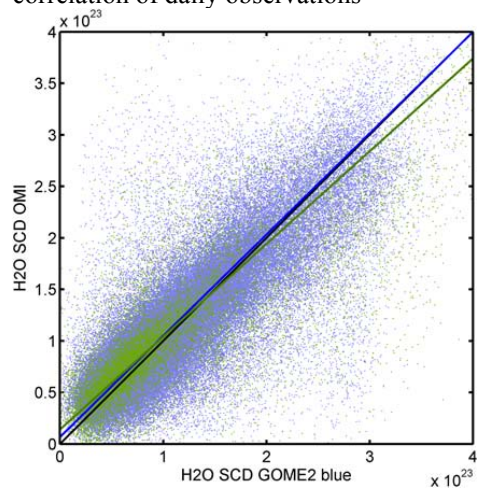

GOME-2 (red) versus GOME-2 (blue),

correlation of monthly averages

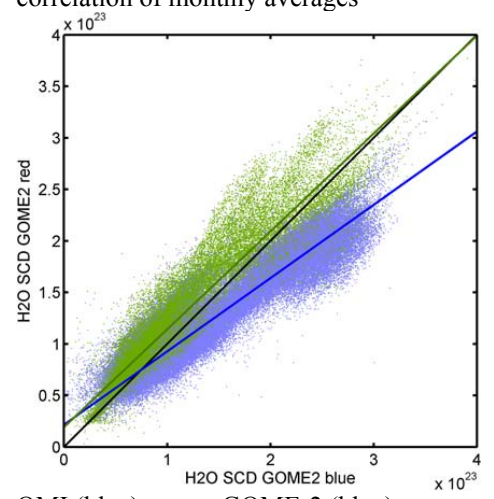

OMI (blue) versus GOME-2 (blue), correlation of monthly averages

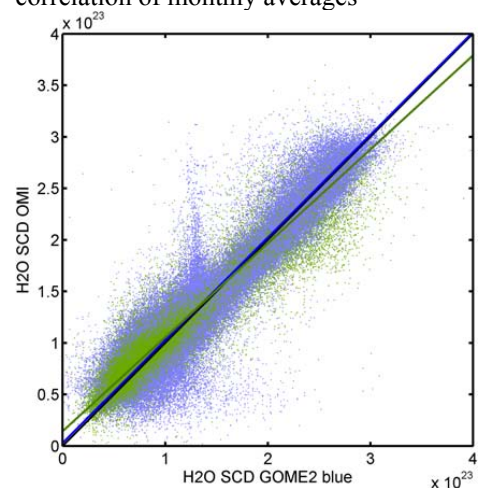

Fig. 12. Correlation analyses for daily observations (left panels; see Fig. 9) and monthly averages (right panels; see Fig. 10) of the $\mathrm{H}_{2} \mathrm{O}$ SCDs (in units of molec $\mathrm{cm}^{-2}$ ). Results (mean values for pixels of $0.5^{\circ} \times 0.5^{\circ}$ ) from the GOME-2 in the red spectral range (top panels) and OMI in the blue spectral range (bottom panels) are plotted versus GOME-2 in the blue spectral range. Green and blue dots represent observations over land and ocean, respectively. The green and blue lines indicate linear fits, the black line represents the one to one line. Slopes, intercepts and correlation coefficients are listed in Table 4.

Table 4. Results of the correlation analyses between the $\mathrm{H}_{2} \mathrm{O}$ DSCD analysed from GOME-2 in the blue spectral range and those from the red spectral range or OMI. For the correlation of monthly data, only measurements with cloud fraction $<10 \%$ were used; for the correlation of daily data, no cloud selection was applied. Note that the correlation results are similar if, for the OMI data, only the same swath width of GOME-2 is considered, and not the full swath width.

\begin{tabular}{lccr}
\hline Comparison & $r^{2}$ & Slope & $\begin{array}{r}y \text { intercept } \\
{\left[10^{21} \text { molec cm }^{-2}\right]}\end{array}$ \\
\hline GOME-2, red, monthly, land & 0.85 & 0.95 & 19.3 \\
GOME-2, red, daily, land & 0.80 & 0.99 & 3.8 \\
GOME-2, red, monthly, ocean & 0.90 & 0.71 & 21.5 \\
GOME-2, red, daily, ocean & 0.84 & 0.83 & 3.1 \\
OMI, blue, monthly, land & 0.88 & 0.91 & 14.5 \\
OMI, blue, daily, land & 0.69 & 0.90 & 14.1 \\
OMI, blue, monthly, ocean & 0.87 & 1.00 & 2.9 \\
OMI, blue, daily, ocean & 0.63 & 0.98 & 6.6 \\
\hline
\end{tabular}

that the scatter of neighbouring observations is much larger than in the red spectral range: over surfaces with high albedo, the scatter (RMS) is about a factor of 15 larger than in the red spectral range, mainly reflecting the difference in the absorption cross sections in both spectral ranges. Over ocean (low surface albedo), the difference in the scatter is much smaller (only about a factor of 6) caused by the higher surface albedo in the blue spectral range. The scatter of the OMI results is about twice that of the GOME- 2 results in the blue spectral range indicating a lower signal-to-noise ratio of the OMI measurements related to the smaller ground pixels.

Based on these findings and on the results of the spectral fitting process, we estimate the detection limit for the analysis of the $\mathrm{H}_{2} \mathrm{O} \mathrm{SCD}$ (for individual ground pixels) in the blue spectral range to about 6 to $18 \times 10^{21}$ molec $\mathrm{cm}^{-2}$ and to about 11 to $32 \times 10^{21}$ molec $\mathrm{cm}^{-2}$ for GOME-2 and OMI, respectively (for the analysis of GOME-2 observations in the red spectral range, the corresponding values are about 0.4 and $3.3 \times 10^{21}$ molec $\mathrm{cm}^{-2}$ ). The lower values correspond to observations over high surface albedo. Here it is interesting to note that high surface albedos (due to ice and snow) typically occur at high latitudes. At these latitudes, usually also the atmospheric light paths are long because of the high SZA. Thus, despite the rather low $\mathrm{H}_{2} \mathrm{O}$ VCDs at high latitudes, the 
$\mathrm{H}_{2} \mathrm{O}$ SCDs are often above the detection limit for observations in the blue spectral range.

In this study, we demonstrated the feasibility of retrieving the atmospheric $\mathrm{H}_{2} \mathrm{O}$ VCD from satellite observations in the blue spectral range. Future studies will address the conversion of the $\mathrm{H}_{2} \mathrm{O}$ SCDs into $\mathrm{H}_{2} \mathrm{O}$ VCDs based on radiative transfer simulations taking into account detailed information about surface albedo, cloud cover and cloud altitude. Also, validation of the $\mathrm{H}_{2} \mathrm{O}$ VCDs by independent data sets is needed to assess the accuracy of the new retrieval for different atmospheric conditions and observation geometries.

Acknowledgements. We like to thank the teams from ESA and EUMETSAT for making the METOP satellite spectral data available. We thank NASA for providing OMI Level 1 data (http://disc. sci.gsfc.nasa.gov/Aura/additional/data-holdings/OMI/index.shtml) and the TEMIS team for poviding surface albedo from GOME (http://www.temis.nl/index.php).

The service charges for this open access publication have been covered by the Max Planck Society.

Edited by: J. Tamminen

\section{References}

Acarreta, J. R., de Haan, J. F., and Stammes, P.: Cloud pressure retrieval using the $\mathrm{O}_{2}-\mathrm{O}_{2}$ absorption band at $477 \mathrm{~nm}$, J. Geophys. Res., 109, D05204, doi:10.1029/2003JD003915, 2004.

Bauer, P. and Schluessel, P.: Rainfall, total water, ice water, and water vapor over sea-polarized microwave simulations and special sensor microwave/image data, J. Geophys. Res., 98, 2073720759, 1993.

Bennartz, R. and Fischer, J.: Retrieval of columnar water vapour over land from back-scattered solar radiation using the Medium Resolution Imaging Spectrometer (MERIS), Remote Sens. Environ., 78, 271-280, 2001.

Bogumil, K., Orphal, J., Homann, T., Voigt, S., Spietz, P., Fleischmann, O. C., Vogel, A., Hartmann, M., Bovensmann, H., Frerik, J., and Burrows, J. P.: Measurements of Molecular Absorption Spectra with the SCIAMACHY Pre-Flight Model: Instrument Characterization and Reference Data for Atmospheric Remote-Sensing in the 230-2380 nm Region, J. Photochem. Photobiol. A, 157, 167-184, 2003.

Deutschmann, T., Beirle, S., Frieß, U., Grzegorski, M., Kern, C., Kritten, L., Platt, U., Pukite, J., Wagner, T., Werner, B., and Pfeilsticker, K.: The Monte Carlo Atmospheric Radiative Transfer Model McArtim: Introduction and Validation of Jacobians and 3D Features, J. Quant. Spectrosc. Ra., 112, 1119-1137, doi:10.1016/j.jqsrt.2010.12.009, 2011.

EUMETSAT: GOME-2 Products Guide, available at: http://oiswww.eumetsat.org/WEBOPS/eps-pg/GOME-2/ GOME2-PG-0TOC.htm (last access: 7 October 2013), 2005.

Held, I. M. and Soden, B. J.: Water vapour feedback and global warming, Annu. Rev. Energ. Env., 25, 441-475, 2000.
Jedlovec, G. J.: An evaluation and comparison of vertical profile data from the VISSR Atmospheric Sounder (VAS), J. Atmos. Ocean. Tech., 2, 559-581, 1985.

Koelemeijer, R. B. A., de Haan, J. F., and Stammes, P.: A database of spectral surface reflectivity in the range $335-772 \mathrm{~nm}$ derived from 5.5 years of GOME observations, J. Geophys. Res., 108, 4070, doi:10.1029/2002JD002429, 2003.

Kurucz, R. L., Furenlid, I., Brault, J., and Testerman, L.: Solar flux atlas from $296 \mathrm{~nm}$ to $1300 \mathrm{~nm}$, National Solar Observatory Atlas No. 1, 1984.

Lang, R. and Lawrence, M. G.: Evaluation of the hydrological cycle of MATCH driven by NCEP reanalysis data: comparison with GOME water vapor measurements, Atmos. Chem. Phys., 5, 887908, doi:10.5194/acp-5-887-2005, 2005.

Lang, R., Williams, J. E., van der Zande, W. J., and Maurellis, A. N.: Application of the Spectral Structure Parameterization technique: retrieval of total water vapor columns from GOME, Atmos. Chem. Phys., 3, 145-160, doi:10.5194/acp-3-145-2003, 2003.

Levelt, P. F. and Noordhoek, R.: OMI Algorithm Theoretical Basis Document Volume I: OMI Instrument, Level 0-1b Processor, Calibration \& Operations, Tech. Rep. ATBD-OMI-01, Version 1.1, 2002.

Maurellis, A. N., Lang, R., van der Zande, W. J., Aben, I., and Ubachs, W.: Precipitable Water Column Retrieval from GOME data, Geophys. Res. Lett., 27, 903-906, 2000.

Mieruch, S., Noël, S., Bovensmann, H., and Burrows, J. P.: Analysis of global water vapour trends from satellite measurements in the visible spectral range, Atmos. Chem. Phys., 8, 491-504, doi:10.5194/acp-8-491-2008, 2008.

Noël, S., Buchwitz, M., Bovensmann, H., Hoogen, R., and Burrows, J. P.: Atmospheric Water Vapor Amounts Retrievd from GOME Satellite data, Geophys. Res. Lett., 26, 1841-1844, 1999.

Noël, S., Mieruch, S., Bovensmann, H., and Burrows, J. P.: Preliminary results of GOME-2 water vapour retrievals and first applications in polar regions, Atmos. Chem. Phys., 8, 1519-1529, doi:10.5194/acp-8-1519-2008, 2008.

Noxon, J. F., Whipple, E. C., and Hyde, R. S.: Stratospheric $\mathrm{NO}_{2}$, 1. Observational method and behaviour at midlatitudes, J. Geophys. Res., 84, 5047-5076, 1979.

Rothman, L. S., Jacquemart, D., Barbe, A., Benner, D. C., Birk, M., Brown, L. R., Carleer, M. R., Chackerian Jr., C., Chance, K., Coudert, L. H., Dana, V., Devi, V. M., Flaud, J.-M., Gamache, R. R., Goldman, A., Hartmann, J.-M., Jucks, K. W., Maki, A. G., Mandin, J.-Y., Massie, S. T., Orphal, J., Perrin, A., Rinsland, C. P., Smith, M. A. H., Tennyson, J., Tolchenov, R. N., Toth, R. A., Vander Auwera, J., Varanasi, P., and Wagner, G.: The HITRAN 2004 molecular spectroscopic database, J. Quant. Spectrosc. Ra., 96, 139-204, 2005.

Rothman, L. S., Gordon, I. E., Barbe, A, Chris Benner, D., Bernath, P. F., Birk, M., Boudon, V., Brown, L. R., Campargue, A., Champion, J.-P., Chance, K., Coudert, L. H., Dana, V., Devi, V. M., Fally, S., Flaud, J.-M., Gamache, R. R., Goldman, A., Jacquemart, D., Kleiner, I., Lacome, N., Lafferty, W. J., Mandin, J.Y., Massie, S. T., Mikhailenko, S. N., Miller, C. E., MoazzenAhmadi, N., Naumenko, O. V., Nikitin, A. V., Orphal, J., Perevalov, V. I., Perrin, A., Predoi-Cross, A., Rinsland, C. P., Rotger, M., Šimečková, M., Smith, M. A. H., Sung, K., Tashkun, S. A., Tennyson, J., Toth, R. A., Vandaele, A. C., and Vander Auw- 
era, J.: The HITRAN 2008 molecular spectroscopic database, J. Quant. Spectrosc. Ra., 110, 533-572, 2009.

Shephard, M. W., Herman, R. L., Fisher, B. M., Cady-Pereira, K. E., Clough, S. A., Payne, V. H., Whiteman, D. N., Comer, J. P., Vömel, H., Miloshevich, L. M., Forno, R., Adam, M., Osterman, G. B., Eldering, A., Worden, J. R., Brown, L. R., Worden, H. M., Kulawik, S. S., Rider, D. M., Goldman, A., Beer, R., Bowman, K. W., Rodgers, C. D., Luo, M., Rinsland, C. P., Lampel, M., and Gunson, M. R.: Comparison of Tropospheric Emission Spectrometer Nadir Water Vapor Retrievals with In Situ Measurements, J. Geophys. Res., 113, D15S24, doi:10.1029/2007JD008822, 2008.

Soden, B. J. and Bretherton, F. P.: Interpretation of TOVS water vapor radiances in terms of layer-average relative humidities: Method and climatology for the upper, middle, and lower troposphere, J. Geophys. Res., 101, 9333-9343, 1996.

Solomon, S., Schmeltekopf, A. L., and Sanders, R. W.: On the interpretation of zenith sky absorption measurements, J. Geophys. Res., 92, 8311-8319, 1987.

Solomon, S., Qin, D., Manning, M., Chen, Z., Marquis, M., Averyt, K. B., Tignor, M., and Miller, H. L. (Eds.): Climate Change: The Physical Science Basis. Contribution of Working Group I to the Fourth Assessment Report of the Intergovernmental Panel on Climate Change, Cambridge University Press, Cambridge, United Kingdom and New York, NY, USA, 2007.

Tobin, C. D., Revercomb, H. E., Knuteson, R. O., Lesht, B. M., Strow, L. L., Hannon, S. E., Feltz, W. F., Moy, L. A., Fetzer, E. J., and Cress, T. S.: Atmospheric Radiation Measurement site atmospheric state best estimates for Atmospheric Infrared Sounder temperature and water vapor retrieval validations, J. Geophys. Res., 111, D09S14, doi:10.1029/2005JD006103, 2006.
Vandaele, A. C., Hermans, C., Simon, P. C., Carleer, M., Colin, R., Fally, S., Mérienne, M.-F., Jenouvrier, A., and Coquart, B.: Measurements of the $\mathrm{NO}_{2}$ Absorption Cross-section from $42000 \mathrm{~cm}^{-1}$ to $10000 \mathrm{~cm}^{-1}(238-1000 \mathrm{~nm})$ at $220 \mathrm{~K}$ and $294 \mathrm{~K}$, J. Quant. Spectrosc. Ra., 59, 171-184, 1997.

Wagner, T., Heland, J., Zöger, M., and Platt, U.: A fast $\mathrm{H}_{2} \mathrm{O}$ total column density product from GOME - Validation with insitu aircraft measurements, Atmos. Chem. Phys., 3, 651-663, doi:10.5194/acp-3-651-2003, 2003.

Wagner, T., Beirle, S., Grzegorski, M., and Platt, U.: Global trends (1996-2003) of total column precipitable water observed by Global Ozone Monitoring Experiment (GOME) on ERS-2 and their relation to near-surface temperature, J. Geophys. Res., 111, D12102, doi:10.1029/2005JD006523, 2006.

Wagner, T., Beirle, S., and Deutschmann, T.: Three-dimensional simulation of the Ring effect in observations of scattered sun light using Monte Carlo radiative transfer models, Atmos. Meas. Tech., 2, 113-124, doi:10.5194/amt-2-113-2009, 2009.

Wagner, T., Beirle, S., and Mies, K.: Description of the MPI-Mainz $\mathrm{H}_{2} \mathrm{O}$ retrieval, technical document, available at: http://www. sciamachy.org/products/H2O/H2Ovc_IUP_AD.pdf (last access: 7 October 2013), 2011.

Wang, P., Stammes, P., van der A, R., Pinardi, G., and van Roozendael, M.: FRESCO+: an improved $\mathrm{O}_{2}$ A-band cloud retrieval algorithm for tropospheric trace gas retrievals, Atmos. Chem. Phys., 8, 6565-6576, doi:10.5194/acp-8-6565-2008, 2008. 